\title{
Acceptance and Commitment Therapy with Pancreatic Cancer: An Integrative Model of Palliative Care-A Case Report
}

\author{
Catherine Virginia F. O'Hayer, ${ }^{1, *}$ Kevin Mitchell O'Hayer, ${ }^{2}$ and Ashwin Sama ${ }^{2}$
}

\begin{abstract}
Background: This case study examines the feasibility of application of an acceptance-based behavioral therapy, acceptance and commitment therapy (ACT), to a patient with end-stage metastatic pancreatic cancer, depression, and anxiety, as a form of integrative palliative care.

Case Presentation: ACT allowed the patient to identify her values of resuming her religious connection, improving relationships with family members and trusted friends, and organizing her affairs before death. As a result, the patient was able to remain engaged in cancer treatments despite side effects that she had previously deemed intolerable. She was able to move toward her values despite health-related and depression-related obstacles. Furthermore, she successfully reconnected with her religious faith, and with her parents, spent time with her family, and deepened relationships with close friends before her death. Her quality of life was much improved by a combination of ACT and cancer treatments, suggesting that ACT may be a feasible mental health adjunct for palliative care in end-stage pancreatic cancer.

Conclusion: ACT was well received by this patient with metastatic pancreatic cancer, improving ability to cope with anxiety, depression, and treatment side effects, thereby accepting and managing her cancer more effectively.
\end{abstract}

Keywords: palliative care; acceptance and commitment therapy; mental health; case report

\section{Introduction}

Acceptance and commitment therapy $\left(\mathrm{ACT}^{1}\right)$ has proven effective in the treatment of depression, anxiety, chronic pain, and substance use. Recent studies suggest that ACT may also be effective for people living with HIV/AIDS ${ }^{2}$ and cystic fibrosis. ${ }^{3}$ ACT differs from traditional cognitive-behavioral therapies in that acceptancebased strategies are used to change one's relationship with distressing thoughts and feelings, rather than targeting thought content directly. ACT's primary goal is to increase experiential acceptance of painful emotions and thoughts, such as depression and fear of dying, thereby eliminating the need for behaviors designed to suppress such emotions (e.g., avoiding treatments to avoid thinking about illness). ACT concurrently promotes motivation to engage in committed action toward one's core values.

\section{Case Report}

The patient, a 54-year-old divorced Caucasian woman, was diagnosed with borderline resectable pancreatic cancer in November 2013 and underwent a classic pancreaticoduodenectomy. Pathology analysis demonstrated a $4 \mathrm{~cm}$ moderately differentiated pancreatic ductal adenocarcinoma with $3 / 12$ lymph nodes positive for metastatic disease and negative margins. On restaging examination before initiation of chemotherapy, she was noted to have a $2.3 \times 2.2 \mathrm{~cm}$ hyperenhancing mass

\footnotetext{
${ }^{1}$ Department of Psychiatry, Drexel University College of Medicine, Philadelphia, Pennsylvania.

${ }^{2}$ Department of Medical Oncology, Thomas Jefferson University Hospital, Philadelphia, Pennsylvania.

*Address correspondence to: Catherine Virginia F. O'Hayer, PhD, Department of Psychiatry, Drexel University College of Medicine, 1427 Vine Street, Mail Stop 984, Philadelphia, PA 19102-1031, E-mail: cvo23@drexel.edu
}

(c) Catherine Virginia F. O'Hayer et al. 2018; Published by Mary Ann Liebert, Inc. This is an Open Access article distributed under the terms of the Creative Commons Attribution License, which permits unrestricted use, distribution, and reproduction in any medium, provided the original work is properly cited. 
abutting the superior mesenteric vein. She was initially treated with gemcitabine for 1 cycle and gemcitabine/ nab-paclitaxel for 2 cycles followed by 50.4 Gy radiation to the tumor bed with concurrent radiosensitizing capecitabine. Scans after her chemoradiation demonstrated metastatic disease in the liver and lungs and gemcitabine and nab-paclitaxel were reinitiated. Throughout the course of treatment, she was noted to have flat affect, tearfulness, and poor social support. She declined the initiation of a selective serotonin reuptake inhibitor for treatment of depressive symptoms; however, she agreed to psychological referral. She was referred to C.V.F.O'H. for treatment of depression as an aspect of palliative care.

\section{Psychiatric Assessment and ACT}

Initially, the patient presented as totally isolated, had not informed her support network of her cancer status, was devoting all available energy toward her job, had "lost her [Catholic] faith" due to diagnosis, and was strongly considering discontinuing treatment ("why bother, all I do is work"). She was diagnosed with Adjustment Disorder with Mixed Anxiety and Depressive Symptoms. She attended five weekly sessions of ACT, summarized in Table 1.

As a result of ACT as a palliative care effort, the patient was able to be present with emotions regarding her mortality, and discuss these with her previously estranged family and girlfriends, allowing her mindfully to make the best use of her remaining time. She recognized that the survival time and symptomatic relief provided by her cancer treatments allowed her to move toward her values of spending time with her family, deepening her relationships with her girlfriends, and getting her affairs in order. ACT also allowed her to gain some emotional distance from the thought that "Cancer is a punishment from God." As a result, she reinstated her strong Catholic faith before her death.

Table 1. Acceptance and Commitment Therapy with Pancreatic Cancer Protocol

\begin{tabular}{|c|c|c|}
\hline Session & ACT targets & Clinical examples \\
\hline 1 & $\begin{array}{l}\text { Creative hopelessness, } \\
\text { identification of values and } \\
\text { obstacles }\end{array}$ & $\begin{array}{l}\text { Patient acknowledged going to great lengths to avoid feeling depressed or anxious, including } \\
\text { avoiding thinking about her diagnosis, and informing only her son of her diagnosis. } \\
\text { Patient identified values of being a loving mother and grandmother, having close } \\
\text { relationships, and being responsible. } \\
\text { Patient is skeptical of treatment and engages primarily in avoidant coping. }\end{array}$ \\
\hline 2 & $\begin{array}{l}\text { Acceptance, being present with } \\
\text { emotions and committed action }\end{array}$ & $\begin{array}{l}\text { Patient hosted her granddaughter for a sleepover and brass band. } \\
\text { Patient was present with emotions associated with her own mortality. } \\
\text { Therapist encouraged patient to prioritize taking action that will move her toward her values } \\
\text { during the time she has left. Patient identified wanting to spend time with her son. }\end{array}$ \\
\hline 3 & $\begin{array}{l}\text { Contact with the present moment } \\
\text { and committed action }\end{array}$ & $\begin{array}{l}\text { Patient arranged time off work to visit her son. } \\
\text { Therapist encouraged patient to be present with emotions associated with the thought } \\
\text { "I don't' have much time left," and the thought "I don't believe in God since diagnosis." } \\
\text { Patient reported urges to discontinue cancer treatment. Therapist encouraged patient } \\
\text { to make a "wise mind" decision about this rather than an emotional one. Patient was able } \\
\text { to be present with emotions regarding this. } \\
\text { Therapist encouraged patient to take action in the service of her value of investing in } \\
\text { relationships. }\end{array}$ \\
\hline 4 & Defusion and acceptance & $\begin{array}{l}\text { Patient spent holidays with family. } \\
\text { Patient plans to disclose her diagnosis to her girlfriends and daughter. } \\
\text { Patient plans to see an attorney to get her will in order. } \\
\text { Patient voiced accepting that remission is no longer possible. She was present with associated } \\
\text { emotions. } \\
\text { Patient identified the strong belief that her "cancer is a punishment from God." Therapist } \\
\text { used defusion strategies to help patient gain some distance from this belief. Therapist } \\
\text { encouraged patient to talk with her priest. } \\
\text { Patient is demonstrating more psychological flexibility regarding her cancer treatment (rather } \\
\text { than quitting altogether, patient is now considering engaging in treatment as a form of } \\
\text { palliative care only). }\end{array}$ \\
\hline 5 & Acceptance and committed action & $\begin{array}{l}\text { Patient informed her girlfriends and coworkers about her diagnosis and prognosis. } \\
\text { Patient noticed feeling "less depressed and emotional" and "more grounded." } \\
\text { Patient contacted her priest and discussed her plan to re-engage with her Catholic faith. } \\
\text { Patient again voiced accepting that remission is impossible and was present with associated } \\
\text { emotions. } \\
\text { Patient reflected on proud moments from her past, some regrets, and hopes for her } \\
\text { remaining time. Patient is committed to continuing to engage in cancer treatments as a } \\
\text { means of palliative care. }\end{array}$ \\
\hline
\end{tabular}


The patient ultimately progressed through her front line metastatic therapy and went on to receive mFOLFIRINOX as second line treatment. During these visits, she arrived with multiple family members including her parents, her son, and one of her close friends. Her disease continued to progress throughout treatment and ultimately, she was placed on hospice and ultimately died on April 6, 2015. It was very clear that her psychological intervention provided significant palliative care and enabled her to connect with her family and friends before death. Pancreatic ductal adenocarcinoma (PDA) is associated with significantly higher rates of depression and anxiety as compared with stage- and prognosismatched advanced tumors of other origins. ${ }^{4}$ Furthermore, early palliative care intervention has improved outcomes among patients with metastatic cancers. ${ }^{5}$ Further studies should be performed to determine whether psychological intervention with ACT can influence outcomes in patients with metastatic PDA.

\section{Author Disclosure Statement}

No competing financial interests exist.

\section{References}

1. Hayes SC, Strosahl KD, Wilson KG. Acceptance and Commitment Therapy: An Experiential Approach to Behavior Change. Guilford: New York, 1999.

2. O'Hayer CVF, Bennett DS, Jacobson J. The lasting impact of HIV/AIDS. In: Mindfulness and Acceptance for Gender \& Sexual Minorities. Skinta M, Curtin A, (eds.). Oakland, CA: New Harbinger, 2016.

3. Bennett DS, O'Hayer CVF, Wolfe WM, et al. ACT with CF-Addressing anxiety and depression among individuals with cystic fibrosis through acceptance and commitment therapy: an in-person and telehealthadapted treatment manual. DUCM Dept Psych. 2016.

4. May M, Schmid RM. Pancreatic cancer and depression: myth and truth. BMC Cancer. 2010;10:569.

5. Temel JS, Greer JA, Muzikansky A, et al. Early palliative care for patients with metastatic non-small cell lung cancer. N Engl J Med. 2010;363: 733-742.

Cite this article as: O'Hayer CVF, O'Hayer KM, Sama A (2018) Acceptance and commitment therapy with pancreatic cancer: an integrative model of palliative care-a case report, Journal of Pancreatic Cancer 4:1, 1-3, DOI: 10.1089/pancan.2017.0021.

\section{Abbreviations Used}

ACT = acceptance and commitment therapy PDA = pancreatic ductal adenocarcinoma

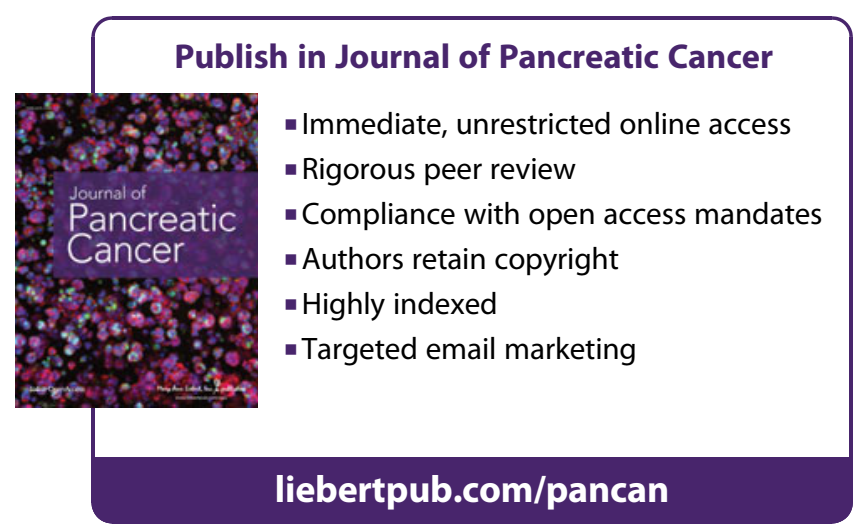

